\title{
Unraveling the molecular components and genetic blueprints of stem cells
}

\author{
Linheng $\mathrm{Li}^{1}$ and Koichi Akashi ${ }^{2}$
}

BioTechniques 35:1233-1239 (December 2003)

\begin{abstract}
Remarkable progress in stem cell biology research over the past few years has provoked a promise for the future of tissue regeneration and gene therapies; so much so, that the use of stem cells in clinical therapy seemed to be just around the corner. However, we now realize there is still a huge task before us to improve our understanding of the nature of stem cells before utilizing them to benefit human health. Stem cell behavior is determined by specific gene products; thus, unraveling the molecular components and genetic blueprints of stem cells will provide important insight into understanding stem cell properties. Here we summarize the research of various groups using microarray technology and other approaches to determine the gene expression profiles in stem cells, particularly in hematopoietic stem cells (HSCs). These works have, to a certain degree, helped to narrow down the candidate genes predominantly expressed in HSCs, revealed a list of stemness genes, and indirectly demonstrated the wide-open chromatin state of stem cells and, with it, the molecular basis of the multipotentiality of stem cells.
\end{abstract}

\section{INTRODUCTION}

Many different methods have been developed for determining differential gene expression. These include subtractive hybridization $(1,2)$, differential display PCR (DD-PCR) (3), representational difference analysis (RDA) (4), expressed sequence tag (EST) analysis (5), serial analysis of gene expression (SAGE) (6), and the nucleic acid array technology (7-10). These technologies have been used for the identification of molecules that are either specifically expressed in hematopoietic stem cells (HSCs) or potentially involved in the regulation of HSC development. For example, a novel DNA sequence was identified from sorted $\mathrm{CD} 34^{+} \mathrm{CD} 38^{\text {lo }}$ hematopoietic progenitor cells using subtractive hybridization (11); both DD-PCR and RDA were used for the isolation of cDNAs from HSC populations $(3,4)$; and a great number of cDNAs have been identified from both human and murine HSC populations using random sequence analysis of ESTs $(12,13)$ and SAGE $(4,14)$.

Each of these technologies has its advantages. Among these technologies, the combination of large-scale cDNA array, microarray, and oligonucleotide arrays affords unprecedented opportunities to systematically analyze gene expression in a given complex biological system and to identify molecules that are involved in the regulation of the development of this system. These tools enable the analysis of not just one gene at a time but thousands or even tens of thousands and allow the comparison of gene sets expressed at various differentiation stages in HSCs. They also assist in the identification of molecules and the underlying genetic pathways that potentially control the developmental switches in HSCs.

The widely used Atlas ${ }^{\mathrm{TM}}$ Array (BD Biosciences Clontech, Palo Alto, CA, USA) is an example of a cDNA array in which cDNAs are deposited at a high density onto nylon filters using a robot. These can be used for either analyzing differential expression genes or defining housekeeping and commonly expressed genes for removal from further analyses. Microarray is another type of robotic system for spotting cDNAs or PCR-amplified cDNA fragments onto glass slides (8). The advantage of microarray is that it allows small-volume hybridization. This is essential for the analysis of material isolated from an extremely limited numbers of HSCs. The microarray system also allows utilization of dualfluorescent dyes and probes derived from different subpopulations of cells, labeled with different fluorescence dyes. This allows for robust comparisons between expression profiles. A variation of this approach is the oligonucleotide array system (GeneChip ${ }^{\circledR}$ 640; Affymetrix, Santa Clara, CA, USA) based on direct synthesis of oligonucleotides onto a silicon surface that are hybridized with the fluorescently labeled target cRNAs derived from tissues or cells $(9,15)$. Given that both the sequence information of human and mouse genomes have been defined and the cost for performing oligonucleotide array hybridization has been reduced, the GeneChip oligonucleotide array has recently gained in popularity.

\footnotetext{
${ }^{1}$ Stowers Institute for Medical Research, Kansas City, MO and ${ }^{2}$ Dana-Farber Cancer Institute, Harvard Medical School, Boston, USA
} 


\section{USING MICROARRAY TO IDENTIFY HEMATOPOIETIC STEM CELL DIFFERENTIALLY EXPRESSED GENES}

The unique property of HSCs is their ability to possess both self-renewal capacity and differentiation potential. Although some signal molecules have been revealed to be involved in the control of self-renewal of HSCs, such as Notch, Wnt, HoxB4, Bmi, and Shh (16-23), the molecular mechanisms that direct stem cells to choose self-renewal rather than differentiation remain largely unknown. At different stages of HSC development, different subpopulations of cells express different sets of genes. This has led to a hypothesis that different sets of expressed genes, in turn, determine the fate of HSCs and the downstream lineage subpopulation (24). It has also been argued that key aspects of stem cell regulation result as a combination of molecular components and/or genetic programs in stem cells (25). Therefore, several different approaches have been used to uncover the molecular components that are specific to HSCs (24-26).

Phillips et al. (25) constructed a PCR-based cDNA library derived from murine fetal liver HSCs (FLHSCs; identified by markers $\left.\mathrm{Lin}^{-} \mathrm{Sca}-1^{+} \mathrm{AA} 4.1^{+} \mathrm{c}-\mathrm{Kit}^{+}\right)$. The FLHSC cDNA library was then subtracted by a secondary cDNA library derived from AA4-1 ${ }^{-}$cells to remove housekeeping genes (25). The subtracted cDNA library, enriched with stem cell-specific genes, was subjected to large-scale sequence analysis, high-density array hybridization, and subsequent bioinformatics annotation. A large number of known genes and ESTs with unknown functions were revealed by this approach (see http://stemcell.princeton.edu). Terskikh et al. (26) took a similar approach but focused on adult bone marrow (BM) cells. Two-hundred twenty-three nonredundant contigs out of 1500 genes/ESTs representing sequences specifically expressed in highly purified HSCs $\left(\mathrm{Lin}^{-} \mathrm{Sca}-1^{+} \mathrm{c}-\right.$ $\mathrm{Kit}^{+}$Thy-1 ${ }^{\mathrm{lo}}$ ) were identified following a subtractive procedure using cDNAs from BM cells (PCR-Select ${ }^{\mathrm{TM}}$ cDNA Subtraction kit; BD Biosciences Clontech). Interestingly, some of the genes that were differentially expressed in the HSC population were also expressed in neurospheres, which are enriched with neural stem cells (NSCs), suggesting that HSCs and NSCs share overlapping genetic programs. For example, $K u 80$, which encodes a DNA binding protein, is required for both lymphogenesis and neurogenesis (27).

In another study, a combined cDNA high-density array and microarray approach was taken to interrogate gene expression profiles in adult HSCs (24). Two cDNA libraries were generated; one derived from rigorously purified HSCs (Lin-Sca$\left.1^{+} \mathrm{c}-\mathrm{Kit}^{+} \mathrm{Thy}-1^{\mathrm{lo}}\right)$ and the other derived from cell populations $\left(\operatorname{Lin}^{-} \mathrm{Sca}-1^{+}\right)$, including both HSCs and early hematopoietic progenitors. These two cDNA libraries were spotted onto nylon filters (cDNA arrays) and hybridized with cDNA probes derived from BM cells to eliminate housekeeping and mature cell-expressed gene products from subsequent analyses. Approximately 5000 genes/ESTs were identified through this subtraction process, and they were then spotted onto glass slides for microarray analysis. Two PCR-amplified cDNA probe sets, one from rhodamine $123(\mathrm{Rh})^{\mathrm{lo}} \mathrm{Lin}^{-} \mathrm{Sca}-1^{+} \mathrm{c}-\mathrm{Kit}^{+}$and the other from $\mathrm{Rh}{ }^{\mathrm{hi}} \mathrm{Lin}^{-} \mathrm{Sca}-{ }^{+}{ }^{+} \mathrm{c}-\mathrm{Kit}^{+}$populations of cells, were hybridized to the microarray of the resultant 5000 genes/ESTs. While the
$\mathrm{Rh}^{\mathrm{lo}} \mathrm{Lin}-\mathrm{Sca}-1^{+} \mathrm{c}-\mathrm{Kit}^{+}$population of cells is enriched with arrested long-term (LT)-HSCs, the $\mathrm{Rh}^{\text {hi }} \mathrm{Lin}^{-} \mathrm{Sca}-{ }^{+}{ }^{+} \mathrm{c}-\mathrm{Kit}^{+}$population is enriched with cycling short-term (ST)-HSCs and multipotent progenitor (MPP) cells (24,28-30). Thus, differentially expressed genes between LT-HSCs and ST-HSCs/MPP cells were identified (see http://db.systemsbiology.net/projects/local/stem_cell/).

Table 1 shows a comparison of differentially expressed HSC genes compiled from these three different approaches (24-26). The components of evolutionally conserved and developmentally regulatory pathways were prominent, including those from the Wnt pathway (Lef1, Tcf4, and Dsh); the TGF- $\beta$ superfamily (BMP4, activin $C$, serine and therine kinases $N I K$ and $S k i)$; the sonic hedgehog (Shh) pathway [smoothened (SMO)]; the Notch family (Notchl and Manic Fringe); members of the homeobox regulatory cascade (Hoxa9, Meis-1, TGIF, and Enx-1); and Bmi. Accumulated evidence indicates that these molecules and the underlying genetic pathways are involved in the regulation of stem cell self-renewal or maintenance. Abnormal activation of the Wnt signal has been associated with intestinal epithelial and other types of tumors $(31,32)$. Activation of the Wnt pathway enhances the self-renewal of HSCs (19). Similarly, the Shh signal pathway is associated with skin basal cell carcinoma and with self-renewal of stem cells $(23,33,34)$. Notchl was identified initially as a gene responsible for a form of T-lymphoma (Tan-1) (35), and its function in maintaining the state of progenitor cells is well-documented (36). Multiple studies have demonstrated the important role of Notch in the maintenance and enhanced repopulation of HSCs (16-18). Cooperation between Hoxa9 and Meis-1 leads to leukemia and is implicated in the regulation of self-renewal of stem cells (37-39). Bmi-1, the suppressor of the Ink4 (itl) locus (encoding p16 and p19 cell growth inhibitors), is essential for the determination of the proliferation potential of $\operatorname{HSCs}(21,22)$.

Several groups have reported gene expression profiles of human HSC and progenitor cells. Human CD34+ ${ }^{+}$HSCs are clinically used in autologous and allogeneic transplantation. Gomes et al. (40) identified 285 genes that are expressed in $\mathrm{CD} 34^{+} \mathrm{HSC}$ and progenitor cells (40). Among these genes, 106 are potential transcriptional factors. A portion of these transcriptional factors has corresponding homologs in murine HSCs, including Tcf4, Runxl, Nfix, TGIF, SKI, Myb, and Bmi (40). It has been shown that transplanting CD34 ${ }^{+}$HSCs from peripheral blood (PB) after mobilization has a higher success rate than using $\mathrm{CD}_{3} 4^{+} \mathrm{HSCs}$ isolated from BM (41). A comparison of the molecular components and the related geneticprogram changes in $\mathrm{CD} 34^{+} \mathrm{HSC}$ under different physiological conditions may explain these clinical findings. Two groups have carried out such a comparison $(41,42)$. They found that the $\mathrm{BM} \mathrm{CD} 34^{+} \mathrm{HSC}$ and progenitor cells express more cell cycle progression genes than the mobilized $\mathrm{PB} \mathrm{CD} 34^{+}$cells, which suggests that the circulating $\mathrm{PB} \mathrm{CD} 34^{+}$cells are more quiescent than those in the BM.

\section{GENE EXPRESSION PROFILING OF STEM CELLS AND STEMNESS GENES}

Stem cells are defined by their common features of self-renewal and pluoripotentiality or multipotentiality. This leads to a hypothesis that all stem cells express a common set of genes 
Table 1. Comparison of Representative Genes Expressed in Hematopoietic Stem Cells (HSCs) That Have Been Identified by Three Groups

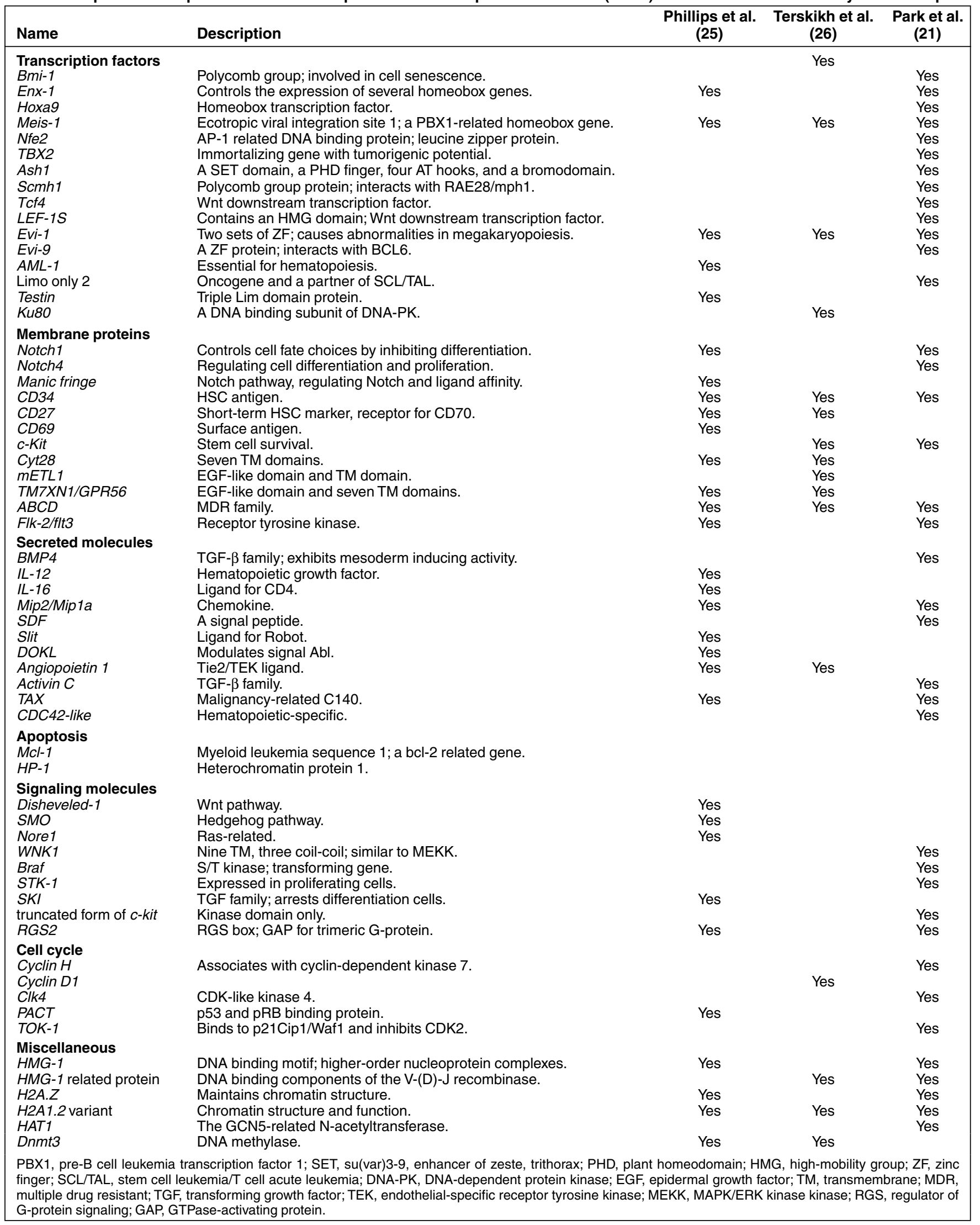




\section{Table 2. Essential Attributes of Stemness}

$\begin{array}{ll}1 & \text { Active JAK/STAT, transforming growth factor- } \beta \text { (TGF- } \beta \text { ), Yes ki- } \\ \text { nase, and Notch signaling. } \\ 2 & \text { The capacity to sense growth hormone and thrombin. } \\ 3 & \text { Interaction with extracellular matrix molecules integrin } \alpha 6 / \beta 1, \\ & \text { Adam9, and bystin. } \\ 4 & \text { Cell cycle regulatory engagement. } \\ 5 & \text { Stress-resistance molecules including DNA repair, protein fold- } \\ & \text { ing, ubiquitin, and deoxyfier systems. } \\ 6 & \text { Chromatin remolding molecules. } \\ 7 & \text { Translational regulation factors. } \\ \text { Adapted from Ramalho-Santos et al. (44). }\end{array}$

and, with their products, determine the special properties of stem cells. Identification of these common genes will provide important insight into understanding the molecular components and the underlying genetic pathways that may be involved in the maintenance and the regulation of self-renewal of stem cells $(43,44)$. However, there are different types of stem cells. Embryonic stem cells (ESCs), generated from the inner cell mass of blastocysts (45), have the totipotent capacity to give rise to all types of tissues in the body and are located at the top of the hierarchical developmental tree (46). Somatic stem cells have a multipotent ability to produce tissue-specific types of cells. Adult HSCs, derived from BM (47), and NSCs, derived from the subventricular zone (SVZ) of the nervous system (48), are two well-characterized somatic stem cells. Identification of the set of commonly expressed genes in these three stem cell populations will unravel the molecular components of stem cells. Two groups have taken the identical approach of using oligonucleotide array technology to compare the gene expression profiles of ESCs, HSCs, and NSCs and have identified lists of genes representing stemness or a stem cell molecular signature $(43,44)$.

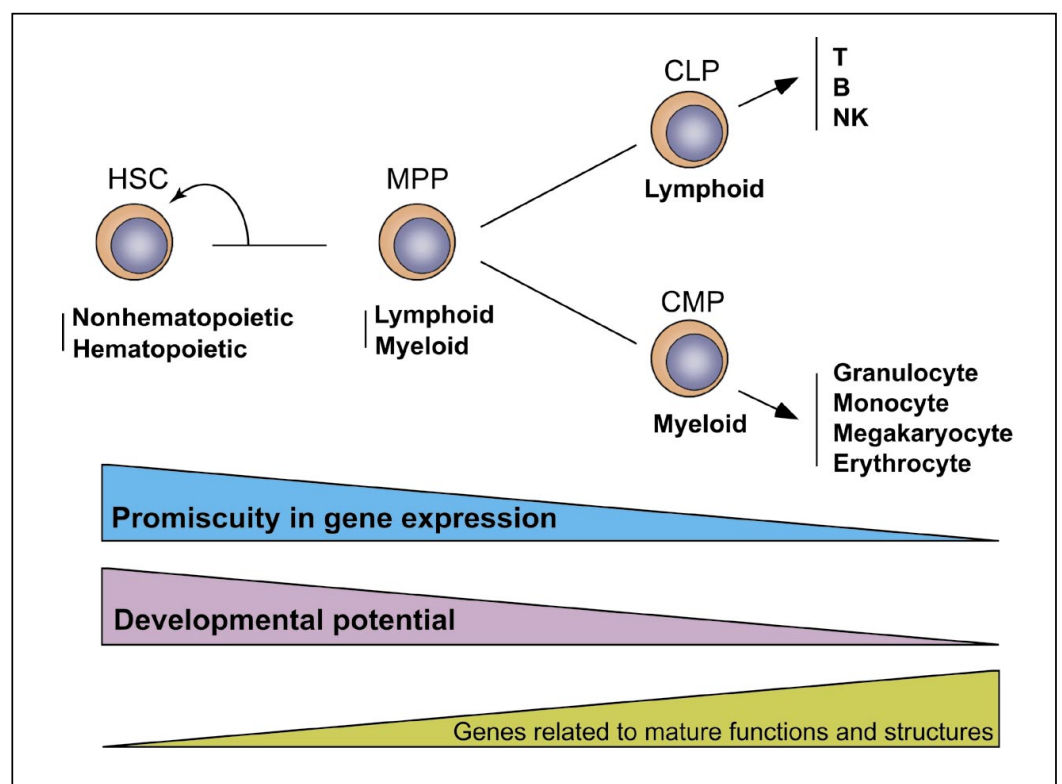

Figure 1. Illustration of changes in accessibility for hematopoietic and nonhematopoietic gene transcriptions during early hematopoiesis. Adapted from Akashi et al. (59). HSC, hematopoietic stem cell; MPP, multipotent progenitor; CLP, common lymphoid progenitor; CMP, common myeloid progenitor; T, T lymphocyte; B, B lymphocyte; NK, natural killer cell.
Ivanova and co-workers (43) have identified 283 genes that are commonly expressed in all ESCs, HSCs, and NSCs (http:// www.sciencemag.org/cgi/content/full/1072530/DC1). These genes fall into different functional categories, such as signal transduction, transcriptional factors, (such as Edr1, EfnB2 Hes1, and Tcf3), translational regulation, cell cycle control, extracellular matrix, chromatin regulation, RNA binding, and apoptosis (43). The expression of $S M O$, encoding a receptor for the $S h h$ signal pathway, is consistent with the role of $S h h$ in enhancing the self-renewal ability of stem cells (23). Several Wnt receptors, Fzd6, 7, and 8, are detected in stem cells, which further supports the role of Wnt in the control of stem cell selfrenewal and fate determination $(31,32)$.

Similarly, Ramalho-Santos et al. (44) have identified 216 stemness genes that are expressed in all three stem cell populations and belong to a variety of functional groups (Table 2).

These are important studies for unraveling the molecular components of stem cells. Burns and Zon (49) have written a comprehensive review comparing these two studies and provide further insight. As discussed in their review, approximately $70 \%$ of the transcripts between fetal and adult HSCs overlap, and $40 \%$ of enriched genes are found in both human and mouse HSCs, further narrowing down the selective gene list. Both groups revealed a list of genes that could potentially play a role in the determination of stem cell behavior. A comparison of the list of stemness genes identified independently by these two groups yielded only 15 common genes $(<10 \%)$; this might be due to a significant difference in methodology, including cell resources and purification, transcript amplification, and data analyses. Recently, using identical statistical methods, Ivanova et al. (50) have reanalyzed the previous data and found 605 overlap genes common to the two sets of their gene list (65.7\% overlap). Nevertheless, for the first time, the two papers provide a snapshot of genes and the underlying regulatory pathways to define stemness. As with other hypotheses, the concept of stemness genes requires further testing to generate more biological evidence. For example, the finding that Nanog is critical for the self-renewal and maintenance of ESCs $(51,52)$ and expressed only in ESCs, but not in NSCs and HSCs, appears to challenge this concept. However, the stemness concept may refer to a broader definition of a specific combination of genes rather than individual genes that endow stem cells with their unique properties.

\section{THE GENERALLY OPEN CHROMATIN STRUCTURE IN HEMATOPOIETIC STEM CELLS MAY DETERMINE THEIR MULTIPOTENTIALITY}

HSCs develop first into MPPs, which then give rise to common lymphoid progenitor (CLP) and common myeloid progenitor (CMP) and finally differentiate into mature blood/immune cells of various types, depending on the differentiation programs that orchestrate transcription of lineage-specific genes. For specific genetic 
programs to be activated, local chromatin must be accessible to transcription machinery $(53,54)$, and it has been shown that activation of chromatin remodeling can occur prior to significant expression of genes in the region of interest $(55,56)$. These results led to the hypothesis that open chromatin structure is maintained in early HSC/MPP cells, enabling multilineage differentiation programs to be readily accessible (57). This priming of genes affiliated with multiple lineages affords flexibility in cell fate decisions and allows multipotent precursors to rapidly respond to environmental cues (58). To examine this process, a global assessment of gene expression during early hematopoiesis (see http://stowers-institute.org/ labs/LiLab/hscdb.asp) reveals that HSCs coexpress both hematopoietic as well as nonhematopoietic genes; MPP cells coexpress a more limited gene set that displays a more hematopoietic-specific character. As cells differentiate into the various hematopoietic progenitors (CMP or CLP), the gene sets available for expression are more and more restricted, reflecting their myeloid or lymphoid lineage commitment (Figure 1). This progressive decrease in the transcription accessibility during differentiation correlates with the stepwise restricted lineage potential of the cells (59). Thus, the generally open chromatin state maintained by HSCs may determine their multipotentiality.

If many genes are in fact primed at MPP stages, then these progenitors should then promiscuously express genes of multiple lineages at the single-cell level. The coexpression of genes related to multiple lineages was confirmed by single-cell reverse transcription PCR (RT-PCR) analyses
(60). Approximately $60 \%$ of single CMPs coexpressed all of these granulocyte/monocyte (GM)- and megakaryocyte/ erythrocyte (MegE)-affiliated genes (Figure 2). In marked contrast, all single GM progenitors (GMPs) expressed GMrelated genes such as myeloperoxidase $(M P O)$ and granulocyte colony-stimulating factor receptor (G-CSFR) but did not express MegE-related genes such as $\beta$-globin or erythropoietin receptor (EpoR) (Figure 2). Conversely, all single MegE progenitors (MEPs) expressed $\beta$-globin and/or EpoR but not $M P O$ or G-CSFR (Figure 2). Myelo-erythroid transcription factors were also coexpressed in single CMPs (60). In the lymphoid pathway, approximately $20 \%$ of single CLPs coexpressed B-lymphoid, Pax-5 and $\lambda 5$, and T-lymphoid CD3 $\delta$ and GATA-3. These data demonstrate directly that the priming of genes of multiple lineages occurs in hematopoietic MPPs such as CMPs and CLPs and suggest that lineage-promiscuous priming might be a common transcriptional feature in uncommitted stem and progenitor cells. Primed genes may represent the full and immediate differentiation potential of each subset assayed (60).

HSCs possess transcriptional accessibility for nonhematopoietic genes associated with multiple organ systems: CD $45^{+}$ HSCs express a great number of nonhematopoietic genes, including genes characteristic of neuronal, endothelial, pancreatic, kidney, liver, heart, hair, epithelial, and muscle cell types (59). These nonhematopoietic genes were expressed in CD $45^{+}$HSCs at the single-cell to 10 -cell level, whereas this broad transcriptional usage is lost as HSCs generate CMPs and CLPs. Thus, in the hematopoietic system, HSCs may
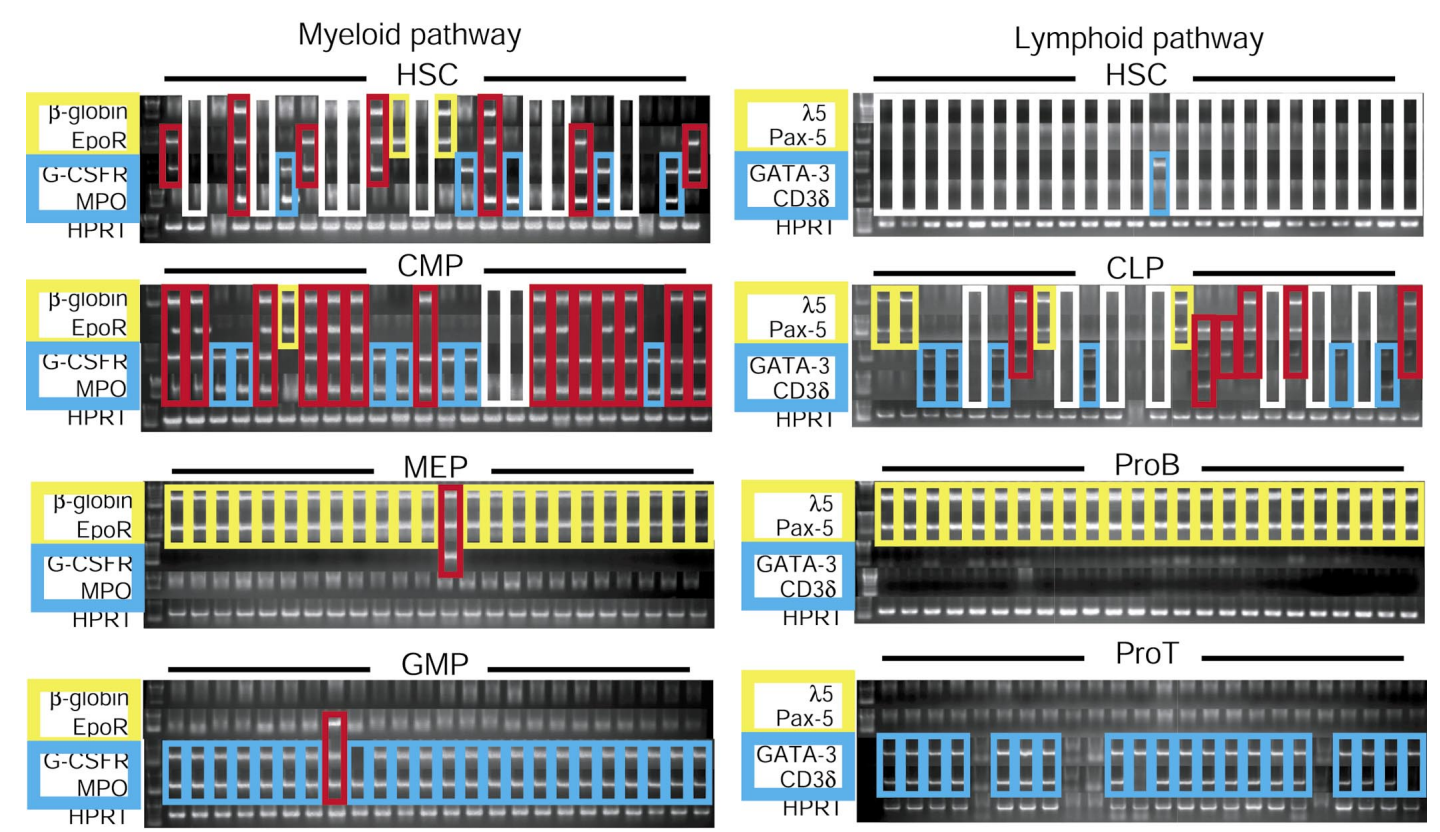

Figure 2. Transcriptional priming stages in single hematopoietic progenitors. Single-cell mutiplex reverse transcription PCR (RT-PCR) assays for myeloidrelated [ $\beta$-globin and erythropoietin receptor (EpoR) for erythroid and granulocyte colony-stimulating factor receptor (G-CSFR) and myeloperoxidase (MPO) for myelomonocytic] and lymphoid-related genes ( $\lambda 5$ and Pax-5 for B lymphoid and GATA-3 and CD $3 \delta$ for T lymphoid). Red boxes indicate lineage promiscuous expression, and the white boxes indicate no expression. More than 50\% of single common myeloid progenitors (CMPs) coexpress both erythroid and myelomonocytic genes, and approximately $20 \%$ of single common lymphoid progenitors (CLPs) coexpress both B and T lymphoid-related genes. These data strongly suggest that $(i)$ the expression of lineage-related genes precedes commitment; (ii) relevant genes are up-regulated upon commitment; and (iii) downregulation of irrelevant genes is likewise important in fate decisions from oligopotent progenitors. This figure was adapted from Miyamoto et al (60). 
maintain accessibility for nonhematopoietic tissues, which may represent their stemness or multipotentiality.

Does the accessibility for nonhematopoietic tissue genes represent HSC ability to transdifferentiate into nonhematopoietic tissue cells? Murine BM reportedly contains cells capable of differentiation into cells homing to multiple organs-including endothelial cells, skeletal and cardiac muscle (61), neurons and glia (62), parenchymal liver cells (63), and/or epithelial cells (64) - in addition to the expected hematopoietic lineages. While these reports suggest that the BM may be special for harboring precursors of nonhematopoietic fates, the notion of HSC plasticity was challenged by a study in which mice reconstituted with single green fluorescent protein $(\mathrm{GFP})^{+}$ HSCs were extensively analyzed for GFP expression in nonhematopoietic tissues (65). These clonal experiments demonstrated that HSCs very rarely contributed to nonhematopoietic fates, suggesting that transdifferentiation of HSCs is unlikely (65). Furthermore, recent reports show that BM cells adopt the phenotype of other tissue cells by spontaneous cell fusion in vitro (66) and suggest that the observed regeneration of hepatocytes following BM transplantation occurs through the cell fusion of damaged hepatocytes and BM-derived cells $(67,68)$. The primed nonhematopoietic gene expression in HSCs may contribute to the reprogramming of gene expression in the genome of the other partner after cell fusion. Nonetheless, transdifferentiation in the settings of increased tissue renewal or tissue damage remains to be precisely addressed using bona fide isolated HSCs. However, because HSCs normally express many nonhematopoietic genes, it will be interesting to determine whether any of these are candidate molecules that instruct nonhematopoietic fate outcomes in definitive HSCs.

\section{CONCLUSION}

Microarray-based gene expression profiling of stem cells provides a fundamental platform for unraveling the molecular components of stem cells. Here we have summarized the research of various groups using microarray technology and other approaches to determine gene expression profiles in stem cells, focusing primarily on HSCs. These works have identified a list of candidate genes that are differentially expressed in HSCs, proposed a new concept of stemness and the underlying stem cell signature genes, and revealed a potential molecular basis of multipotentiality of stem cells as a wide-open chromatin state in stem cells. The integration of this enormous fund of information in conjunction with other approaches, including molecular, cellular, genetic, and developmental biology, to eventually uncover the mystery of stem cells will be the challenge for all stem cell biologists.

\section{ACKNOWLEDGMENTS}

We appreciate proofreading and editing by Dr. L.M. Wiedemann and D. di Natale. We are grateful to Drs. I. Lemischka and D. Melton for providing the data of reanalysis of stemness genes. We apologize for those whose papers are not cited here due to limited space; it does not mean their works are not significant. L.L. is supported by the Stowers Institute for Medical Research.

\section{REFERENCES}

1.Sive, H.L. and T. St. John. 1988. A simple subtractive hybridization technique employing photoactivatable biotin and phenol extraction. Nucleic Acids Res. 16:10937.

2.Duguid, J.R., R.G. Rohwer, and B. Seed. 1988. Isolation of cDNAs of scrapie-modulated RNAs by subtractive hybridization of a cDNA library. Proc. Natl. Acad. Sci. USA 85:5738-5742.

3.Liang, P. and A.B. Pardee. 1992. Differential display of eukaryotic messenger RNA by means of the polymerase chain reaction. Science 257:967-971.

4.Lisitsyn, N., N. Lisitsyn, and M. Wigler. 1993. Cloning the differences between two complex genomes. Science 259:946-951.

5.Adams, M.D., M.B. Soares, A.R. Kerlavage, C. Fields, and J.C. Venter 1993. Rapid cDNA sequencing (expressed sequence tags) from a directionally cloned human infant brain cDNA library. Nat. Genet. 4:373-380.

6.Velculescu, V.E., L. Zhang, B. Vogelstein, and K.W. Kinzler. 1995. Serial analysis of gene expression. Science 270:484-487.

7.Pietu, G., O. Alibert, V. Guichard, B. Lamy, F. Bois, E. Leroy, R. MariageSampson, R. Houlgatte, et al. 1996. Novel gene transcripts preferentially expressed in human muscles revealed by quantitative hybridization of a high density cDNA array. Genome Res. 6:492-503.

8.Schena, M., D. Shalon, R.W. Davis, and P.O. Brown. 1995. Quantitative monitoring of gene expression patterns with a complementary DNA microarray. Science 270:467-470.

9.Lockhart, D.J., H. Dong, M.C. Byrne, M.T. Follettie, M.V. Gallo, M.S. Chee, M. Mittmann, C. Wang, et al. 1996. Expression monitoring by hybridization to high-density oligonucleotide arrays. Nat. Biotechnol. 14: 1675-1680.

10.Blanchard, A.P. and L. Hood. 1996. Sequence to array: probing the genome's sercrets. Nat. Biotechnol. 14:1649.

11.Graf, L. and B. Torok-Storb. 1995. Identification of a novel DNA sequence differentially expressed between normal human CD34+CD38hi and CD34+CD38lo marrow cells. Blood 86:548-556.

12.Yang, Y., K.R. Peterson, G. Stamatoyannopoulos, and T. Papayannopoulou. 1996. Human CD34+ cell EST database: single-pass sequencing of 402 clones from a directional cDNA library. Exp. Hematol. 24:605-612.

13.Gu, J., Q.H. Zhang, Q.H. Huang, S.X. Ren, X.Y. Wu, M. Ye, C.H. Huang, G. Fu, et al. 2000. Gene expression in CD34(+) cells from normal bone marrow and leukemic origins. Hematol. J. 1:206-217.

14.Zhou, G., J. Chen, S. Lee, T. Clark, J.D. Rowley, and S.M. Wang. 2001. The pattern of gene expression in human CD34(+) stem/progenitor cells. Proc. Natl. Acad. Sci. USA 98:13966-13971.

15.Lockhart, D.J. and E.A. Winzeler. 2000. Genomics, gene expression and DNA arrays. Nature 405:827-836.

16.Li, L., L. Milner, Y. Deng, M. Iwata, A. Banta, L. Graf, S. Marcovina, C. Friedman, et al. 1998. Human homolog of rat Jagged1 expressed by marrow stroma inhibits differentiation of 32D cells through interaction with Notch1. Immunity $8: 43-55$.

17.Varnum-Finney, B., L. Xu, C. Brashem-Stein, C. Nourigat, D. Flowers, S. Bakkour, W.S. Pear, and I.D. Bernstein. 2000. Pluripotent, cytokine-dependent, hematopoietic stem cells are immortalized by constitutive Notch1 signaling. Nat. Med. 6:1278-1281

18.Milner, L.A. and A. Bigas. 1999. Notch as a mediator of cell fate determination in hematopoiesis: evidence and speculation. Blood 93:2431-2448.

19.Reya, T., A.W. Duncan, L. Ailles, J. Domen, D.C. Scherer, K. Willert, L. Hintz, R. Nusse, et al. 2003. A role for Wnt signalling in self-renewal of haematopoietic stem cells. Nature 423:409-414.

20.Antonchuk, J., G. Sauvageau, and R.K. Humphries. 2002. HOXB4-induced expansion of adult hematopoietic stem cells ex vivo. Cell 109:39-45.

21.Park, I.K., D. Qian, M. Kiel, M.W. Becker, M. Pihalja, I.L. Weissman, S.J. Morrison, and M.F. Clarke. 2003. Bmi-1 is required for maintenance of adult self-renewing haematopoietic stem cells. Nature 423:302-305.

22.Lessard, J. and G. Sauvageau. 2003. Bmi-1 determines the proliferative capacity of normal and leukaemic stem cells. Nature 423:255-260.

23.Bhardwaj, G., B. Murdoch, D. Wu, D.P. Baker, K.P. Williams, K. Chadwick, L.E. Ling, F.N. Karanu, et al. 2001. Sonic hedgehog induces the proliferation of primitive human hematopoietic cells via BMP regulation. Nat. Immunol. 2:172-180.

24.Park, I., Y. He, F. Lin, O.D. Laerum, Q. Tian, R. Bumgarner, C. Klug, K. Li, et al. 2002. Differential gene expression profiling of adult murine hematopoietic stem cells. Blood 99:488-498.

25.Phillips, R.L., R.E. Ernst, B. Brunk, N. Ivanova, M.A. Mahan, J.K. 
Deanehan, K.A. Moore, G.C. Overton, et al. 2000. The genetic program of hematopoietic stem cells. Science 288:1635-1640.

26.Terskikh, A.V., M.C. Easterday, L. Li, L. Hood, H.I. Kornblum, D.H. Geschwind, and I.L. Weissman. 2001. From hematopoiesis to neuropoiesis: evidence of overlapping genetic programs. Proc. Natl. Acad. Sci. USA 98 7934-7939.

27.Gu, Y., J. Sekiguchi, Y. Gao, P. Dikkes, K. Frank, D. Ferguson, P. Hasty, J. Chun, et al. 2000. Defective embryonic neurogenesis in Ku-deficient but not DNA-dependent protein kinase catalytic subunit-deficient mice. Proc. Natl. Acad. Sci. USA 97:2668-2673.

28.Spangrude, G.J. and G.R. Johnson. 1990. Resting and activated subsets of mouse multipotent hematopoietic stem cells. Proc. Natl. Acad. Sci. USA 87: 7433-7437.

29.Morrison, S.J., A.M. Wandycz, H.D. Hemmati, D.E. Wright, and I.L. Weissman. 1997. Identification of a lineage of multipotent hematopoietic progenitors. Development 124:1929-1939.

30.Zijlmans, J.M., J.W. Visse, K. Kleiverda, P.M. Kluin. R. Willemze, and W.E. Fibbe. 1995. Modification of rhodamine staining allows identification of hematopoietic stem cells with preferential short-term or long-term bone marrow-repopulating ability. Proc. Natl. Acad. Sci. USA 92:8901-8905.

31.Cadigan, K.M. and R. Nusse. 1997. Wnt signaling: a common theme in animal development. Genes Dev. 11:3286-3305.

32.Taipale, J. and P.A. Beachy. 2001. The hedgehog and Wnt signaling pathways in cancer. Nature 411:349-354.

33.Chiang, C., R.Z. Swan, M. Grachtchouk, M. Bolinger, Y. Litingtung, E.K. Robertson, M.K. Cooper, W. Gaffield, et al. 1999. Essential role for sonic hedgehog during hair follicle morphogenesis. Dev. Biol. 205:1-9.

34.Zhang, Y. and D. Kalderon. 2001. Hedgehog acts as a somatic stem cell factor in the Drosophila ovary. Nature 410:599-604

35.Ellisen, L.W., J. Bird, D.C. West, A.L. Soreng, T.C. Reynolds, S.D. Smith, and J. Sklar. 1991. TAN-1, the human homolog of Drosophila Notch gene, is broken by chromosomal translocations in T lymphoblastic neoplasms. Cell 66:649-661.

36.Artavanis-Tsakonas, S., K. Matsuno, and M.E. Fortini. 1995. Notch signaling. Science 268:225-232

37.Lawrence, H.J., S. Rozenfeld, C. Cruz, K. Matsukuma, A. Kwong, L. Komuves, A.M. Buchberg, and C. Largman. 1999. Frequent co-expression of the HOXA9 and MEIS1 homeobox genes in human myeloid leukemias. Leukemia 13:1993-1999.

38.Calvo, K.R., D.B. Sykes, M.P. Pasillas, and M.P. Kamps. 2002. Nup98HoxA9 immortalizes myeloid progenitors, enforces expression of Hoxa9, Hoxa7 and Meis1, and alters cytokine-specific responses in a manner similar to that induced by retroviral co-expression of Hoxa9 and Meis1. Oncogene 21: 4247-4256.

39.Calvo, K.R., P.S. Knoepfler, D.B. Sykes, M.P. Pasillas, and M.P. Kamps. 2001. Meis1a suppresses differentiation by G-CSF and promotes proliferation by SCF: potential mechanisms of cooperativity with Hoxa9 in myeloid leukemia. Proc. Natl. Acad. Sci. USA 98:13120-13125.

40.Gomes, I., T.T. Sharma, S. Edassery, N. Fulton, B.G. Mar, and C.A. Westbrook. 2002. Novel transcription factors in human CD34 antigen-positive hematopoietic cells. Blood 100:107-119.

41.Graf, L., S. Heimfeld, and B. Torok-Storb. 2001. Comparison of gene expression in CD34+ cells from bone marrow and G-CSF-mobilized peripheral blood by high-density oligonucleotide array analysis. Biol. Blood Marrow Transplant. 7:486-494.

42.Steidl, U., R. Kronenwett, U.P. Rohr, R. Fenk, S. Kliszewski, C. Maercker, P. Neubert, M. Aivado, et al. 2002. Gene expression profiling identifies significant differences between the molecular phenotypes of bone marrowderived and circulating human CD34+ hematopoietic stem cells. Blood 99: 2037-2044.

43.Ivanova, N.B., J.T. Dimos, C. Schaniel, J.A. Hackney, K.A. Moore, and I.R. Lemischka. 2002. A stem cell molecular signature. Science 298:601604

44.Ramalho-Santos, M., S. Yoon, Y. Matsuzaki, R.C. Mulligan, and D.A. Melton. 2002. "Stemness": transcriptional profiling of embryonic and adult stem cells. Science 298:597-600.

45.Thomson, J.A., J. Itskovitz-Eldor, S.S. Shapiro, M.A. Waknitz, J.J. Swiergiel, V.S. Marshall, and J.M. Jones. 1998. Embryonic stem cell lines derived from human blastocysts. Science 282:1145-1147.

46.Weissman, I.L. 2000. Stem cells: units of development, units of regeneration, and units in evolution. Cell 100:157-168.

47.Spangrude, G.J., S. Heimfeld, and I.L. Weissman. 1988. Purification and characterization of mouse hematopoietic stem cells. Science 241:58-62

48.Weissman, I.L., D.J. Anderson, and F. Gage. 2001. Stem and progenitor cells: origins, phenotypes, lineage commitments, and transdifferentiations. Annu. Rev. Cell Dev. Biol. 17:387-403.

49.Burns, C.E. and L.I. Zon. 2002. Portrait of a stem cell. Dev. Cell 3:612-613.

50.Ivanova, N., J.T. Dimos, C. Schaniel, J.A. Hackney, and K.A. Moore. Response to comments on "'Stemness': transcriptional profiling of embryonic and adult stem cells" and "A stem cell molecular signature". Science 302:393

51.Chambers, I., D. Colby, M. Robertson, J. Nichols, S. Lee, S. Tweedie, and A. Smith. 2003. Functional expression cloning of Nanog, a pluripotency sustaining factor in embryonic stem cells. Cell 113:643-655.

52.Mitsui, K., Y. Tokuzawa, H. Itoh, K. Segawa, M. Murakami, K. Takahashi, M. Maruyama, M. Maeda, et al. 2003. The homeoprotein Nanog is required for maintenance of pluripotency in mouse epiblast and ES cells. Cell 113:631-642.

53.Berger, S.L. 2001. Molecular biology. The histone modification circus. Science 292:64-65.

54.Felsenfeld, G., J. Boyes, J. Chung, D. Clark, and V. Studitsky. 1996 Chromatin structure and gene expression. Proc. Natl. Acad. Sci. USA 93: 9384-9388.

55.Weintraub, H. 1985. Assembly and propagation of repressed and depressed chromosomal states. Cell 42:705-711.

56.Kontaraki, J., H.H. Chen, A. Riggs, and C. Bonifer. 2000. Chromatin fine structure profiles for a developmentally regulated gene: reorganization of the lysozyme locus before trans-activator binding and gene expression. Genes Dev. 14:2106-2122.

57.Cross, M.A. and T. Enver. 1997. The lineage commitment of haemopoietic progenitor cells. Curr. Opin. Genet. Dev. 7:609-613.

58.Hu, M., D. Krause, M. Greaves, S. Sharkis, M. Dexter, C. Heyworth, and T. Enver. 1997. Multilineage gene expression precedes commitment in the hemopoietic system. Genes Dev. 11:774-785.

59.Akashi, K., X. He, J. Chen, H. Iwasaki, C. Niu, B. Steenhard, J. Zhang, J. Haug, at al. 2003. Transcriptional accessibility for genes of multiple tissues and hematopoietic lineages is hierarchically controlled during early hematopoiesis. Blood 101:383-389.

60.Miyamoto, T., H. Iwasaki, B. Reizis, M. Ye, T. Graf, I.L. Weissman, and K. Akashi. 2002. Myeloid or lymphoid promiscuity as a critical step for hematopoietic lineage commitment. Dev. Cell 3:137-147.

61.Orlic, D., J. Kajstura, S. Chimenti, D.M. Bodine, A. Leri, and P. Anversa. 2001. Transplanted adult bone marrow cells repair myocardial infarcts in mice. Ann. NY Acad. Sci. 938:221-230.

62.Priller, J., A. Flugel, T. Wehner, M. Boentert, C.A. Haas, M. Prinz, F. Fernandez-Klett, K. Prass, et al. 2001. Targeting gene-modified hematopoietic cells to the central nervous system: use of green fluorescent protein uncovers microglial engraftment. Nat. Med. 7:1356-1361.

63.Lagasse, E., H. Connors, M. Al-Dhalimy, M. Reitsma, M. Dohse, L. Osborne, X. Wang, M. Finegold, et al. 2000. Purified hematopoietic stem cells can differentiate into hepatocytes in vivo. Nat. Med. 6:1229-1234.

64.Krause, D.S., N.D. Theise, M.I. Collector, O. Henegariu, S. Hwang, R. Gardner, S. Neutzel, and S.J. Sharkis. 2001. Multi-organ, multi-lineage engraftment by a single bone marrow-derived stem cell. Cell 105:369-377.

65.Wagers, A.J., R.I. Sherwood, J.L. Christensen, and I.L. Weissman. 2002 Little evidence for developmental plasticity of adult hematopoietic stem cells. Science 297:2256-2259.

66.Terada, N., T. Hamazaki, M. Oka, M. Hoki, D.M. Mastalerz, Y. Nakano, E. Meyer, L. Morel, et al. 2002. bone marrow cells adopt the phenotype of other cells by spontaneous cell fusion. Nature 416:542-545

67.Wang, X., H. Willenbring, Y. Akkari, Y. Torimaru, M. Foster, M. AlDhalimy, E. Lagasse, M. Finegold, et al. 2003. Cell fusion is the principal source of bone-marrow-derived hepatocytes. Nature 422:897-901.

68.Vassilopoulos, G., P.R. Wang, and D.W. Russell. 2003. Transplanted bone marrow regenerates liver by cell fusion. Nature 422:901-904.

Address correspondence to:

Linheng Li

Stowers Institute for Medical Research

Kansas City, MO 64110, USA

e-mail: lil@stowers-institute.org 